\title{
Glutamine protection in an experimental model of acetaminophen nephrotoxicity
}

\author{
Marco A. Brovedan, Sara M. Molinas, Gerardo B. Pisani, Liliana A. Monasterolo, and Laura Trumper
}

\begin{abstract}
Acetaminophen (APAP) is a widely prescribed analgesic and antipyretic drug. In the present work, we studied the effects of glutamine (Gln) in an in vivo model of APAP-induced nephrotoxicity in male Wistar rats. Renal function, histological characteristics, and $\mathrm{Na}^{+}, \mathrm{K}^{+}$-ATPase cortical abundance and distribution were analyzed. The appearance of HSP70 and actin in urine was also evaluated. Myeloperoxidase (MPO) activity in cortical tissue was measured as an index of the inflammatory response. Gln administration 30 min before APAP protected from the renal functional and histological damage promoted by APAP. Rats that received the dual treatment Gln and APAP (Gln/APAP) showed the same level of $\mathrm{Na}^{+}, \mathrm{K}^{+}$-ATPase cortical induction as APAP-treated animals, but the enzyme maintained its normal basolateral localization. HSP70 abundance was increased up to the same level in the Gln, APAP, and Gln/APAP groups. Urinary HSP70 and actin were detected only in the APAP-treated animals, reinforcing the protection of renal tubular integrity afforded by the Gln pretreatment. Gln pretreatment also protected from the increment in MPO activity promoted by APAP. Our results support the idea that Gln pretreatment could be a therapeutic option to prevent APAP-induced renal injury.
\end{abstract}

Key words: kidney, acetaminophen, glutamine, HSP70, $\mathrm{Na}^{+} ; \mathrm{K}^{+}$-ATPase, nephrotoxicity.

Résumé : L’acétaminophène (APAP) est un médicament analgésique et antipyrétique prescrit couramment. Dans les présents travaux, nous avons étudié les effets de la glutamine (Gln) dans un modèle in vivo de néphrotoxicité engendrée par l'APAP chez le rat Wistar mâle. Nous avons analysé la fonction rénale et les caractéristiques histologiques, ainsi que la quantité et la distribution de $\mathrm{Na}^{+}, \mathrm{K}^{+}$-ATPase au sein du cortex rénal. Nous avons aussi évalué l'apparition d'HSP70 et d'actine dans l'urine. Nous avons mesuré l'activité de la myéloperoxydase (MPO) dans le tissu cortical, comme indice de la réaction inflammatoire. L'administration de Gln $30 \mathrm{~min}$ avant celle de l'APAP entraînait une protection contre les dommages rénaux fonctionnels et histologiques favorisés par l'APAP. Les rats qui étaient exposés à la Gln et à l'APAP (Gln/APAP) ont montré les mêmes taux d'induction de la $\mathrm{Na}^{+}, \mathrm{K}^{+}-\mathrm{ATPase}$ dans le cortex que les animaux exposés à l'APAP seule, mais l'enzyme permettait de maintenir sa localisation basolatérale normale. Les taux d'HSP70 augmentaient dans une même mesure dans les groupes Gln, APAP et Gln/APAP. Nous avons décelé des HSP70 et de l'actine uniquement dans l'urine des animaux exposés à l'APAP seule, ce qui soutient la protection de l'intégrité des tubules rénaux permise par l'exposition préalable à la Gln. L'exposition préalable à la Gln permettait aussi une protection contre l'augmentation de l'activité de la MPO favorisée par l'APAP. Nos résultats appuient l'idée selon laquelle l'exposition préalable à la Gln pourrait constituer une option de traitement visant à prévenir les lésions rénales engendrées par l'APAP. [Traduit par la Rédaction]

Mots-clés : rein, acétaminophène, glutamine, HSP70, $\mathrm{Na}^{+} ; \mathrm{K}^{+}$-ATPase, néphrotoxicité.

\section{Introduction}

Ischemia and nephrotoxins are the main causes of acute kidney injury. Although the kidney can completely recover from an insult that results in cell death, acute kidney injury is still a significant clinical problem (Bonventre and Yang 2011).

Acetaminophen (APAP) is a widely prescribed analgesic and antipyretic drug. It is considered safe in therapeutic doses, but in overdose situations, it produced liver necrosis and renal injury in humans and in experimental animal models (Boyer and Rouff 1971; Cobden et al. 1982; Mour et al. 2005). In a previous work, we reported the development of APAP-induced acute renal failure after the administration of a single toxic dose of APAP to male
Wistar rats. Sixteen hours after APAP administration, we observed an impairment of renal hemodynamic and tubular functions. Renal function recovered $48 \mathrm{~h}$ after APAP intoxication (Trumper et al. 1992). In isolated proximal tubular cells incubated with APAP, the detachment of $\mathrm{Na}^{+}, \mathrm{K}^{+}$-ATPase from its membrane anchoring was observed (Trumper et al. 2005). It is known that the $70 \mathrm{kDa}$ family of heat shock proteins (HSP70) plays a major role in cellular protection (Aufricht 2005). HSP70 has been involved in the restitution of the $\mathrm{Na}^{+}, \mathrm{K}^{+}$-ATPase cytoskeletal anchorage (Aufricht et al. 1998; Bidmon et al. 2000).We observed an increase of HSP70 abundance in the renal cortex after APAP administration and HSP70 was detected in urines from the intoxicated animals (Molinas et al. 2010).

Received 21 June 2017. Accepted 19 September 2017.

M.A. Brovedan. Pharmacology, Faculty of Biochemical and Pharmaceutical Sciences, National University of Rosario, Suipacha 531, 2000 Rosario, Argentina.

S.M. Molinas and L.A. Monasterolo. Pharmacology, Faculty of Biochemical and Pharmaceutical Sciences, National University of Rosario, Suipacha 531, 2000 Rosario, Argentina; National Council of Scientific and Technical Research (CONICET).

G.B. Pisani. Morphology, Faculty of Biochemical and Pharmaceutical Sciences, National University of Rosario, Suipacha 531, 2000 Rosario, Argentina. L. Trumper. Pharmacology, Faculty of Biochemical and Pharmaceutical Sciences, National University of Rosario, Suipacha 531, 2000 Rosario, Argentina; Research Council of the National University of Rosario (CIC-UNR).

Corresponding author: Laura Trumper (email: ltrumper@fbioyf.unr.edu.ar).

Copyright remains with the author(s) or their institution(s). Permission for reuse (free in most cases) can be obtained from RightsLink. 
HSP70 induction has been cytoprotective to several injuries, including oxidative stress (Donati et al. 1990), ischemia (Van Why et al. 1992; Schober et al. 1997; Wang et al. 2011), and nephrotoxicity (Komatsuda et al. 1993; Cowley and Gudapaty 1995). Based on previous evidence, we hypothesize that HSP inducers could represent a therapeutic tool against APAP-induced nephrotoxicity.

Glutamine (Gln) is the most abundant free amino acid in the body and plays a central role in the promotion and maintenance of several organ functions (Curi et al. 2005). It has been shown that Gln can safely enhance HSP expression in in vitro and in vivo models of injury (Hamiel et al. 2009). Moreover, it has been established that HSP induction was necessary for the protective effects of Gln (Morrison et al. 2006; Singleton and Wischmeyer 2007). Actually, Gln is the only physiologically relevant inducer of the heat shock response (Ziegler et al. 2005).

The aim of our present work was to study the effects of Gln in an in vivo model of APAP-induced nephrotoxicity. Renal function, histological characteristics, and $\mathrm{Na}^{+}, \mathrm{K}^{+}$-ATPase cortical abundance and distribution were analyzed. The appearance of HSP70 and actin in urine was also evaluated. Myeloperoxidase (MPO) activity in cortical tissue was measured as an index of the inflammatory response.

\section{Material and methods}

\section{Animals and treatments}

Male Wistar rats (300-350 g) were used. Animals were housed in rooms with standard laboratory conditions (regular $12 \mathrm{~h}$ light cycles at $21-23^{\circ} \mathrm{C}$ ) and had free access to a standard diet and tap water until used. Experiments were performed in accordance with the Guide for the Care and Use of Laboratory Animals (8th ed., 2011, published by The National Academies Press, USA) and approved by our institutional ethics committee.

Rats were fasted for $17 \mathrm{~h}$ (5:00 p.m. to 10:00 a.m.) before the experiments and had free access to water. They were housed in metabolic cages (Nalgene Labware, Rochester, New York, USA) for a $16 \mathrm{~h}$ urinary collection period (6:00 p.m. to 10:00 a.m.). A 2 day acclimation time was allowed before experiments were initiated. On the third day, four groups $(n=4-6)$ were studied as follows. (1) Animals that received a single dose of APAP (Sigma Chemical Co., St. Louis, Missouri, USA), $1000 \mathrm{mg} / \mathrm{kg}$ body mass i.p. at $0.5 \mathrm{~mL} /$ $100 \mathrm{~g}$ body mass in propylene glycol - saline (1:1), before the collection period (APAP). This dose of APAP was previously described as nephrotoxic in male Wistar rats (Trumper et al. 1992). (2) Animals injected with Gln as alanyl glutamine (Sigma Chemical Co.), $0.75 \mathrm{mg} / \mathrm{kg}$ body mass i.p. at $0.375 \mathrm{~mL} / 100 \mathrm{~g}$ body mass in distilled water adjusted to $\mathrm{pH} 5.4,30 \mathrm{~min}$ before the administration of APAP (Gln/APAP). The dipeptide was used because it has a higher solubility than Gln alone (Wischmeyer et al. 2003). (3) Animals injected with Gln $30 \mathrm{~min}$ before the collection period (Gln). (4) Animals that received the corresponding volume of vehicles (control). The dose and timing of Gln administration were based on previous studies (Fuller et al. 2007; Singleton and Wischmeyer 2007).

At the end of the collection period, animals were anesthetized with ketamine (100 mg/kg body mass i.p.) and xilacine ( $3 \mathrm{mg} / \mathrm{kg}$ body mass i.p.). Blood was collected from the inferior vena cava and kidneys were promptly removed. Plasma was separated immediately for the measurement of creatinine and urea. Urine volume was recorded and urinary creatinine, $\mathrm{Na}^{+}$, and $\mathrm{K}^{+}$were determined.

\section{Histopathological studies}

Following standard procedures, the excised kidneys were processed for light microscopic observation. The tissue was fixed in $10 \%$ formaldehyde, embedded in paraffin, and sectioned $(5 \mu \mathrm{m})$. The sections were stained with haematoxylin and eosin or periodic acid - Schiff's and examined under a light microscope.

\section{$\mathrm{Na}^{+}, \mathrm{K}^{+}$-ATPase $\alpha 1$ subunit immunohistochemistry}

Kidney slices were fixed in $10 \%(v / v)$ phosphate buffer (PB) formalin solution, $\mathrm{pH} 7.40$, and embedded in low melting point paraffin. Briefly, $4 \mu \mathrm{m}$ paraffin sections were placed in $3 \%$ hydrogen peroxide in $\mathrm{PB}$ for $15 \mathrm{~min}$ to inhibit the endogenous peroxidase activity and heated at $96^{\circ} \mathrm{C}$ in $10 \mathrm{mmol} / \mathrm{L}$ citrate buffer for $10 \mathrm{~min}$. Slices were blocked for $1 \mathrm{~h}$ at room temperature in $1 \%$ bovine serum albumin in PB. The sections were incubated with $\alpha 1$ subunit $\mathrm{Na}^{+}, \mathrm{K}^{+}$-ATPase antibody (1:50 dilution; Santa Cruz Biotechnology, Dallas, Texas, USA) at $4{ }^{\circ} \mathrm{C}$ for $24 \mathrm{~h}$ and subsequently incubated with biotinylated goat anti-rabbit immunoglobulin and streptavidinHRP (HRP CytoSkan detection kit). Immunoreactivity was detected with $2.7 \mathrm{mmol} / \mathrm{L}$ 3,3'-diaminobenzidine tetrahydrochloride in PB with $0.03 \%$ hydrogen peroxide $(w / v)$. The reaction was stopped by adding distilled water. Sections were lightly counterstained with haematoxylin. As a negative control, the primary antibody was replaced with normal rabbit serum in PB.

\section{Preparation of renal cortical homogenates}

After having been excised, the kidneys were decapsulated and placed on a buffered solution ( $150 \mathrm{mmol} / \mathrm{L} \mathrm{NaCl}, 10 \mathrm{mmol} / \mathrm{L}$ Tris, $1 \mathrm{mmol} / \mathrm{L}$ EDTA, and $1 \mathrm{mmol} / \mathrm{L}$ phenylmethanesulfonyl fluoride, $\mathrm{pH}$ 7.5). All steps were performed at $4{ }^{\circ} \mathrm{C}$. The cortex was dissected out and minced. Cortex was homogenized in the buffer $(5 \mathrm{~mL} / \mathrm{g}$ of tissue) in a motor-driven Teflon-glass Potter homogenizer (10 strokes at $800 \mathrm{rpm}$ ) and then centrifuged at $680 \mathrm{~g}$ for $10 \mathrm{~min}$. The pellets consisting of nuclei and unbroken cells were discarded. The supernatants were stored at $-70{ }^{\circ} \mathrm{C}$ until use within a few days.

\section{Gel electrophoresis and immunoblotting}

Samples of renal cortical homogenates (10 $\mathrm{g}$ of protein) and urine (20 $\mu \mathrm{g}$ of protein) were run on sodium dodecyl sulfate $-8 \%$ polyacrylamide gels (Laemmli 1970) (Bio-Rad Mini Protean 3; Hercules, California, USA), as described previously (Trumper et al. 2000; Molinas et al. 2010). For the detection of the $\mathrm{Na}^{+}, \mathrm{K}^{+}$-ATPase $\alpha_{1}$ subunit, nitrocellulose membranes were incubated for $1 \mathrm{~h}$ at room temperature with $5 \%(w / v)$ nonfat dry milk in Tris-buffered saline with $0.05 \%$ Tween 20 followed by a $1 \mathrm{~h}$ (room temperature) incubation with a polyclonal antibody to $\mathrm{Na}^{+}, \mathrm{K}^{+}$-ATPase $\alpha_{1}$ subunit (1:7000 dilution; Santa Cruz Biotechnology). After that, blots were washed and incubated with the horseradish peroxidase conjugated corresponding secondary antibody (DakoCytomation, Glostrup, Denmark). Protein bands were detected with an enhanced chemiluminescence detection system (Pierce). Autoradiographs were obtained by exposing the membranes to Kodak XAR films (Eastman Kodak, Rochester, New York, USA).

In renal cortical homogenates and in urine samples, HSP70 levels were detected by sodium dodecyl sulfate - $8 \%$ polyacrylamide gels and Western blotting as described previously (Molinas et al. 2010) using an anti-HSP70 goat polyclonal antibody (1:1000 dilution; Santa Cruz Biotechnology) and an alkaline phosphatase conjugated anti-goat antibody. Membranes of cortical homogenates were stripped and reprobed with a rabbit polyclonal anti-actin antibody (1:500 dilution; Sigma-Aldrich). Protein bands were detected with an enhanced chemiluminescence detection system.

To detect actin in urine samples, membranes were incubated with primary antibody to actin (1:200 dilution; Sigma-Aldrich) and detection was achieved by enhanced chemiluminescence detection system. Blots were digitized and densitometry analyses were performed with the Adobe PhotoShop (6.0) computer program.

\section{Renal MPO activity}

MPO activity was measured in cortical homogenates as previously described (Pompermayer et al. 2005). To verify MPO heat resistance, the tubes were incubated in a water bath for $2 \mathrm{~h}$ at $60{ }^{\circ} \mathrm{C}$ (Schierwagen et al. 1990) and then centrifuged for $15 \mathrm{~min}$ at $10000 \mathrm{~g}$ at $4{ }^{\circ} \mathrm{C}$. MPO activity in the supernatants was assayed by measuring the change in optical density at $652 \mathrm{~nm}$. Results are expressed as changes in optical density per gram of tissue. 
Fig. 1. Glutamine (Gln) protected against the acetaminophen (APAP) induced diminution in glomerular filtration rate (GFR) and increments in creatinine and urea levels. Rats were treated with $\mathrm{Gln}$ at $0.75 \mathrm{mg} / \mathrm{kg}$ body mass i.p. or vehicle $30 \mathrm{~min}$ before the administration of APAP at $1000 \mathrm{mg} / \mathrm{kg}$ body mass i.p. (Gln/APAP or APAP, respectively) or vehicle (Gln or control, respectively). Data are mean \pm SEM of four to six experiments. ${ }^{*} p<0.05$ compared with the control, ${ }^{* *} p<0.01$ compared with the control, ${ }^{\#} p<0.05$ compared with APAP, and ${ }^{\# \#} p<0.01$ compared with APAP.

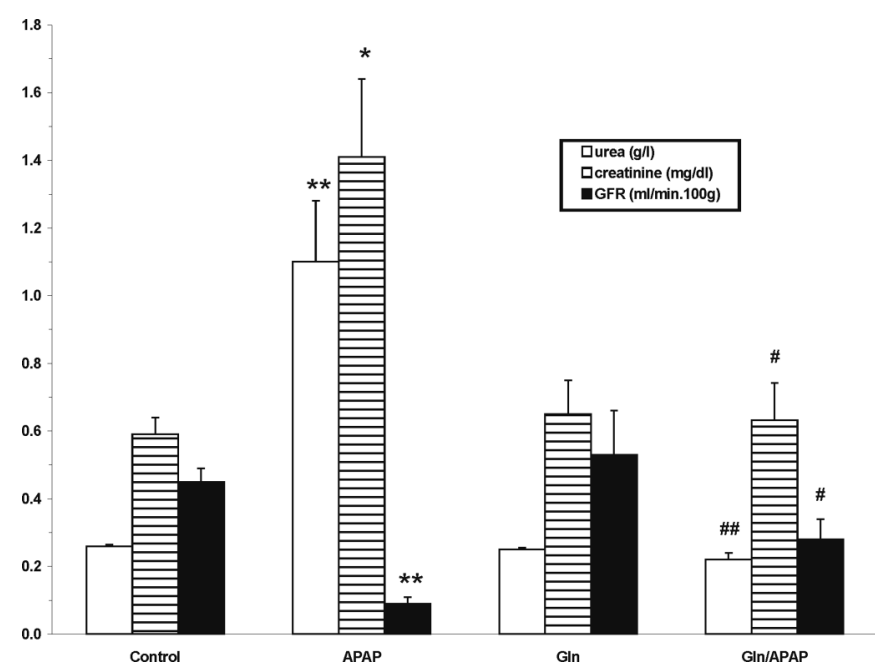

\section{Analytical methods}

Plasma and urinary creatinine were determined by a kinetic alkaline picrate method (Jaffé reaction) with a commercial kit (Wiener Laboratories, Rosario, Argentina). Urea was measured with commercial kits (Wiener Laboratories). The volume of urine was estimated gravimetrically. Sodium and potassium were measured by flame photometry. Fractional excretion of water (urine volume per minute glomerular filtration rate (GFR)), sodium, and potassium (clearance of sodium and potassium GFR) was calculated with the use of conventional formulae. Proteins were measured with Coomasie brilliant blue G250 (Sedmak and Grossberg 1977).

\section{Statistical analysis}

Data are expressed as mean \pm SEM. Statistics were performed using the one-way ANOVA followed by Newman-Keuls contrasts. The 0.05 level of probability was used as the criterion of significance in all cases.

\section{Results}

Effect of Gln on APAP-induced renal functional alterations

Plasma creatinine and urea levels were significantly increased and GFR was significantly decreased after the administration of a toxic dose of APAP. Gln did not alter GFR or plasma creatinine or urea levels compared with control values. Prior treatment with Gln followed by APAP protected against APAP-induced diminution of GFR and the increments of plasma urea and creatinine levels. All data are shown in Fig. 1. As shown in Table 1, urine flow rate decreased after APAP administration. Fractional excretion of sodium, potassium, and water was significantly increased in the rats intoxicated with APAP. Gln prevented the alterations in urinary flow and tubular parameters promoted with APAP intoxication. Gln alone had no effects on these parameters.

\section{Effect of Gln on APAP-induced morphological alterations}

Morphological alterations after APAP treatment were evaluated by light microscopy. Figures $2 a-2 d$ show sections stained with haematoxylin and eosin $(200 \times)$. Figures $2 e-2 h$ show sections stained with periodic acid - Schiff's (400x). Kidneys studied after APAP admin-
Table 1. Urine flow and tubular parameters in control rats and rats receiving acetaminophen (APAP), glutamine (Gln), and the dual treatment $\mathrm{G} \ln / \mathrm{APAP}$.

\begin{tabular}{lccll}
\hline & Control & APAP & Gln & Gln/APAP \\
\hline Urine flow $\left(\mathrm{mL} \cdot \mathrm{min}^{-1} \cdot 100 \mathrm{~g}^{-1}\right)$ & $3.9 \pm 0.5$ & $2.1 \pm 0.2^{*}$ & $2.8 \pm 0.2$ & $3.1 \pm 0.3^{\#}$ \\
Fractional excretion $\mathrm{H}_{2} \mathrm{O}(\%)$ & $0.9 \pm 0.2$ & $2.8 \pm 0.4^{*}$ & $0.5 \pm 0.1$ & $0.6 \pm 0.1^{\# \#}$ \\
Fractional excretion $\mathrm{Na}^{+}(\%)$ & $0.2 \pm 0.05$ & $0.6 \pm 0.1^{*}$ & $0.2 \pm 0.03$ & $0.3 \pm 0.1^{\#}$ \\
Fractional excretion $\mathrm{K}^{+}(\%)$ & $11.8 \pm 2.8$ & $41.4 \pm 8.6^{*}$ & $7.9 \pm 1.1$ & $8.4 \pm 1.9^{\#}$ \\
\hline
\end{tabular}

Note: Each result is the mean \pm SEM. ${ }^{*} p<0.05$ compared with the control, ${ }^{\#} p<0.05$ compared with APAP, and ${ }^{\# \#} p<0.01$ compared with APAP.

Fig. 2. Effects of acetaminophen (APAP), glutamine (Gln), and the dual treatment Gln/APAP on renal histology. Rats were treated with Gln at $0.75 \mathrm{mg} / \mathrm{kg}$ body mass i.p. or vehicle $30 \mathrm{~min}$ before the administration of APAP at $1000 \mathrm{mg} / \mathrm{kg}$ body mass i.p. (Gln/APAP or APAP, respectively) or vehicle (Gln or control, respectively). Tissue sections from kidneys of ( $a$ and $e$ ) control, ( $b$ and $f$ ) APAP, ( $c$ and $g$ ) Gln, and ( $d$ and $h$ ) Gln/APAP rats are shown. Figures $4 a-4 d$ show sections stained with haematoxylin and eosin (200x) and Figs. 4e-4h show sections stained with periodic acid - Schiff's (400x). The asterisk shows desquamated tubular cells, the open arrowhead shows vacuolization of tubular cells, the solid arrowhead shows tubular casts, the arrow shows areas of diminished brush border, and the hash shows areas of cellular tumefaction.
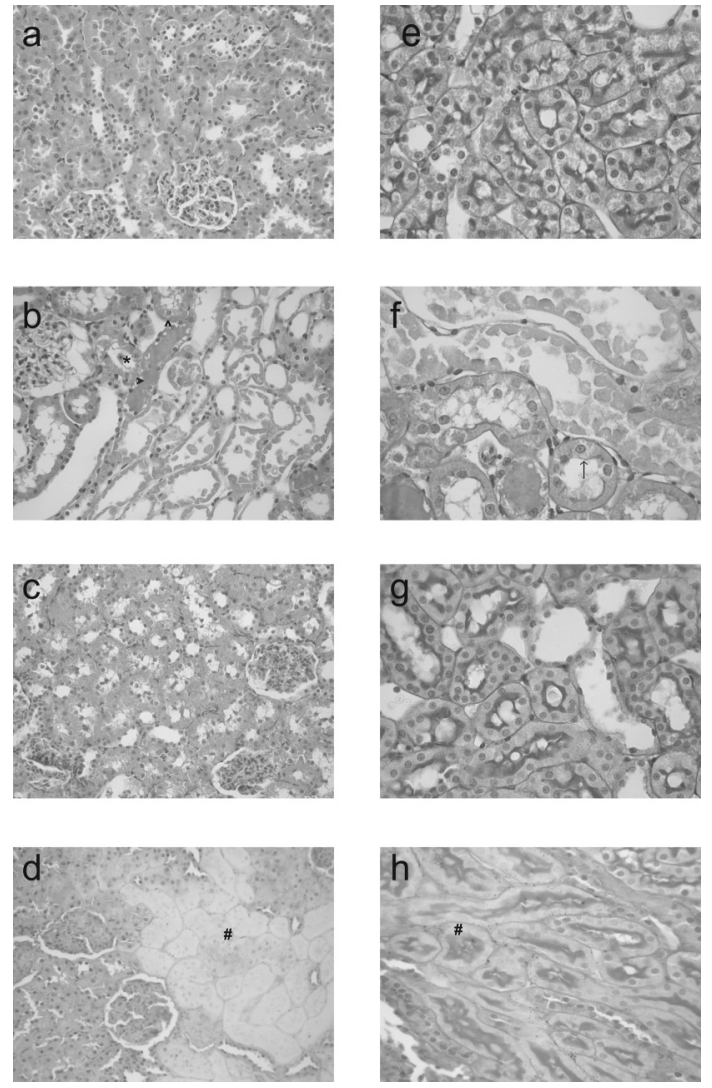

istration showed severe cortical necrosis, lumen dilatation, vacuolization of tubular cell cytoplasm, abundant tubular casts, some of them with cellular detritus, and a marked diminution of the brush border (Figs. $2 b$ and 2f). Kidneys from rats that received Gln (Figs. $2 c$ and $2 g$ ) did not differ from control kidneys (Figs. $2 a$ and $2 e$ ). Kidneys from animals that received Gln previous to APAP (Figs. $2 d$ and $2 h$ ) showed an important degree of preservation of morphological structure and a preserved brush border. However, in these kidneys, some areas of cellular tumefaction were observed. This is probably a consequence of the osmotic swelling of 
Fig. 3. Glutamine (Gln) pretreatment did not prevent the increment in $\mathrm{Na}^{+}, \mathrm{K}^{+}$-ATPase abundance in cortical tissue induced by acetaminophen (APAP). Rats were treated with Gln at $0.75 \mathrm{mg} / \mathrm{kg}$ body mass i.p. or vehicle $30 \mathrm{~min}$ before the administration of APAP at $1000 \mathrm{mg} / \mathrm{kg}$ body mass i.p. (Gln/APAP or APAP, respectively) or vehicle (Gln or control, respectively). (a) Representative Western blot showing the immunodetectable $\mathrm{Na}^{+}, \mathrm{K}^{+}$-ATPase $\alpha 1$ subunit; (b) ratio between the $\mathrm{Na}^{+}, \mathrm{K}^{+}$-ATPase $\alpha 1$ subunit and actin abundance in arbitrary densitometry units. Each result is the mean \pm SEM of four to six experiments. ${ }^{*} p<0.05$ compared with the control.

a
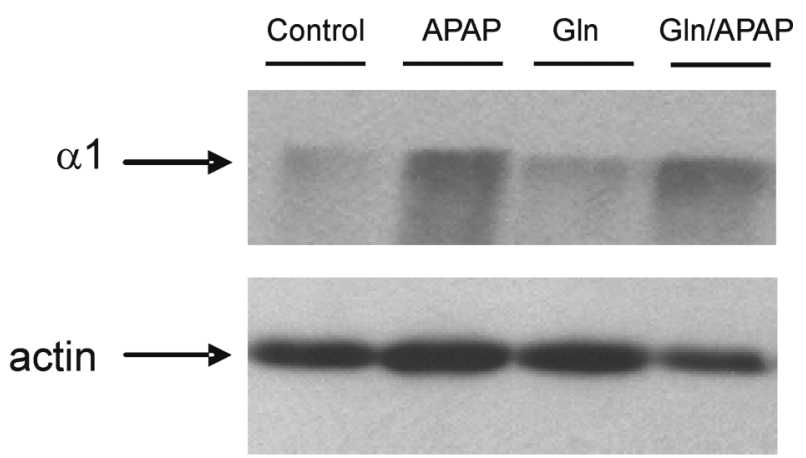

b

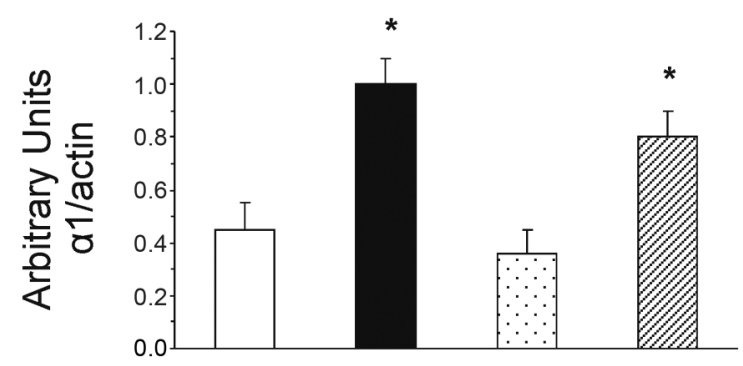

the cells caused by the transport of Gln into the cells via a sodiumdependent transporter (Curi et al. 2005). Glomeruli were preserved in all of the experimental groups studied.

Effect of Gln on APAP-induced alterations in cortical $\mathrm{Na}^{+}, \mathrm{K}^{+}$-ATPase protein levels and its cellular localization

Protein levels of the $\mathrm{Na}^{+}, \mathrm{K}^{+}-\mathrm{ATPase} \alpha 1$ subunit were evaluated by Western blot analysis in cortical tissue homogenates. As we have shown in a previous work (Trumper et al. 2000), APAP promoted an increment of the $\mathrm{Na}^{+}, \mathrm{K}^{+}$-ATPase $\alpha 1$ subunit in cortical homogenates. Gln administration did not promote any change in protein level in cortical homogenates. Gln previous to APAP intoxication did not prevent the increment promoted by APAP alone. All of these results are presented in Fig. 3.

We also analyzed the localization of $\mathrm{Na}^{+}, \mathrm{K}^{+}$-ATPase in the cortical tissue. As shown in Fig. $4 a$, in control kidneys, $\mathrm{Na}^{+}, \mathrm{K}^{+}$-ATPase was localized in basolateral membranes. In the APAP group (Fig. 4b), the pattern of distribution of the enzyme was basolateral and cytoplasmic. Gln did not modify the normal pattern of distribution (Fig. 4c). Gln pretreatment was able to prevent the redistribution of $\mathrm{Na}^{+}, \mathrm{K}^{+}$-ATPase promoted by APAP (Fig. $4 d$ ).

\section{Effect of APAP, Gln, and the dual treatment Gln/APAP on} cortical HSP70 induction

As shown in Fig. 5, HSP70 was constitutively expressed in the renal cortex from control rats. HSP70 levels were increased in cortical tissue obtained from rats intoxicated with APAP. Gln promoted the induction of HSP70. The administration of Gln previous to APAP did not modify the levels of HSP70 achieved with APAP or Gln alone.
Fig. 4. Glutamine (Gln) pretreatment prevents the redistribution $\mathrm{Na}^{+}, \mathrm{K}^{+}$ATPase in cortical tissue induced by acetaminophen (APAP). Photographs (200x) were obtained from $(a)$ control rats, $(b)$ rats treated with APAP at $1000 \mathrm{mg} / \mathrm{kg}$ body mass i.p, (c) rats treated with Gln at $0.75 \mathrm{mg} / \mathrm{kg}$ body mass i.p., and (d) rats treated with $\mathrm{Gln}$ at $0.75 \mathrm{mg} / \mathrm{kg}$ body mass i.p. $30 \mathrm{~min}$ before the administration of APAP at $1000 \mathrm{mg} / \mathrm{kg}$ body mass i.p.
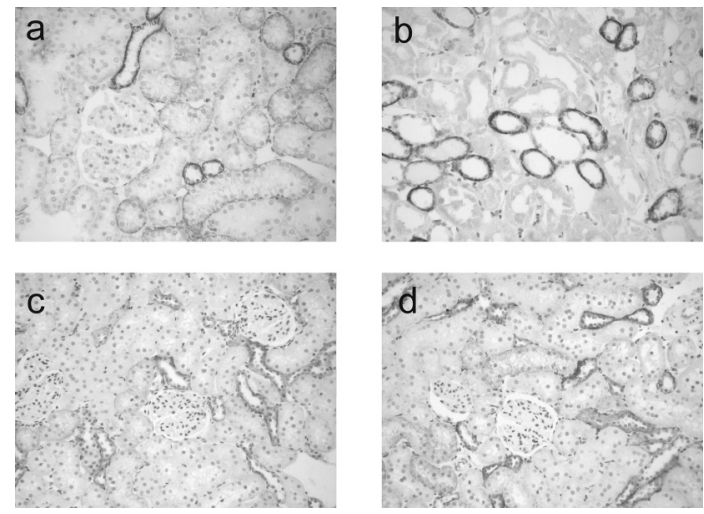

Fig. 5. HSP70 abundance in cortical tissue. Rats were treated with glutamine (Gln) at $0.75 \mathrm{mg} / \mathrm{kg}$ body mass i.p. or vehicle $30 \mathrm{~min}$ before the administration of acetaminophen (APAP) at $1000 \mathrm{mg} / \mathrm{kg}$ body mass i.p. (Gln/APAP or APAP, respectively) or vehicle (Gln or control, respectively). (a) Representative Western blot showing immunodetectable HSP70; (b) ratio between HSP70 and actin abundance in arbitrary densitometry units. Each result is the mean \pm SEM of four to six experiments. ${ }^{*} p<0.05$ compared with the control.

a
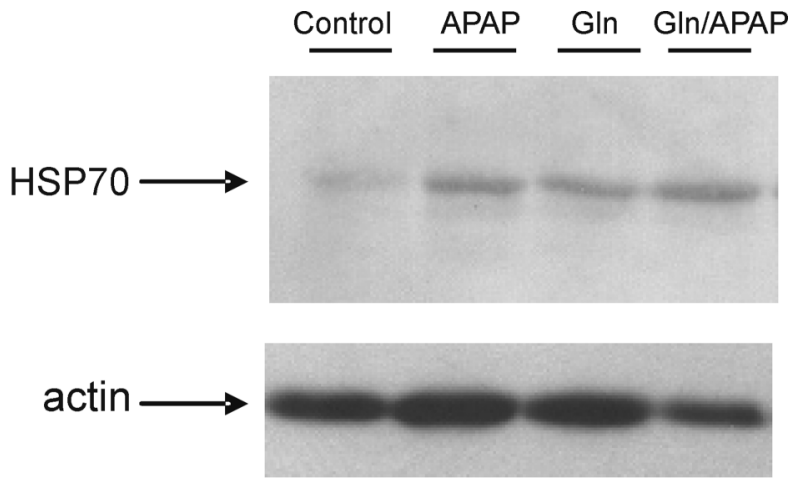

b

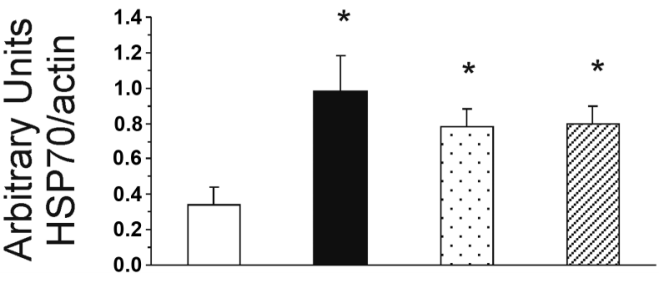

\section{Urinary HSP70 and actin excretion}

In urine from control rats, there was no detectable HSP70. HSP70 was detected in the urines from the APAP treated group. No HSP70 was detected in urine from rats that received Gln alone or the dual treatment Gln/APAP (Fig. 6a), suggesting preservation of renal tubular integrity.

The appearance of actin in urine is an identified marker of tubular damage (Coux et al. 2002; Kwon et al. 2003). As shown in Fig. $6 b$, actin appeared in the urine from APAP-treated rats. Actin 
Fig. 6. Glutamine (Gln) pretreatment prevents the appearance of HSP70 and actin in urine promoted by acetaminophen (APAP). Representative immunoblot of HSP70 and actin detection in urines. Rats were treated with Gln at $0.75 \mathrm{mg} / \mathrm{kg}$ body mass i.p. or vehicle $30 \mathrm{~min}$ before the administration of APAP at $1000 \mathrm{mg} / \mathrm{kg}$ body mass i.p. (Gln/APAP or APAP, respectively) or vehicle (Gln or control, respectively).

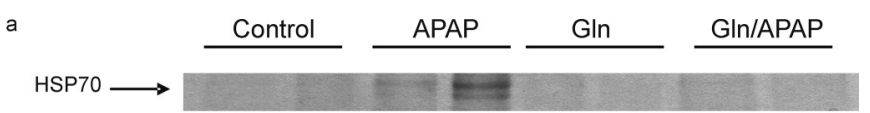

b

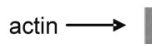

Fig. 7. Glutamine (Gln) pretreatment prevented the increment in mieloperoxidase activity (MPO) activity (optical density (OD)) in cortical tissue induced by acetaminophen (APAP). Rats were treated with Gln at $0.75 \mathrm{mg} / \mathrm{kg}$ body mass i.p. or vehicle $30 \mathrm{~min}$ before the administration of APAP at $1000 \mathrm{mg} / \mathrm{kg}$ body mass i.p. (Gln/APAP or APAP, respectively) or vehicle (Gln or Control, respectively). Data are mean \pm SEM of four to six experiments. ${ }^{* * *} p<0.001$ compared with the control and ${ }^{\# \# \#} p<0.001$ compared with APAP.

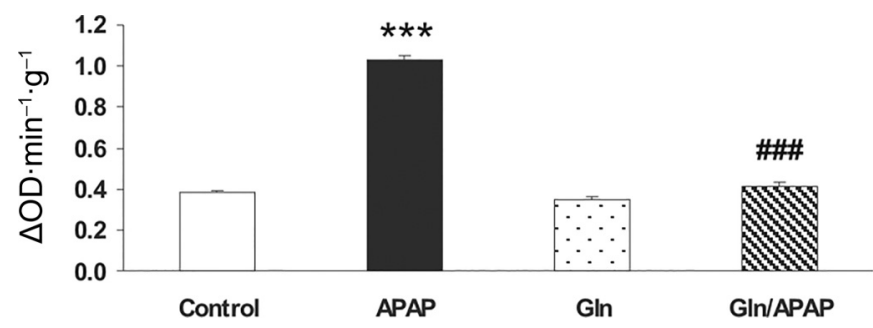

was not detected in urines from control rats, rats that received Gln, or rats that received the dual treatment Gln/APAP.

Effect of APAP, Gln, and the dual treatment GLN/APAP on MPO activity in cortical tissue

Cortical MPO activity was significantly increased after APAP treatment. The dual treatment Gln/APAP abolished this increment. The results are shown in Fig. 7.

\section{Discussion}

APAP is a widely prescribed analgesic and antipyretic drug. Although it is safe at therapeutic doses, it can produce hepatic and renal damage in an overdose situation. There are several mechanisms that are activated during kidney injury to compensate for the resultant damage. One known compensatory mechanism is the upregulation of HSPs (Aufricht 2005). HSP induction has shown a therapeutic potential in many injury conditions (Van Why et al. 1992; Komatsuda et al. 1993). Gln is one of the most abundant amino acids in the bloodstream and it is known to induce the heat shock response (Ziegler et al. 2005). In the present work, we studied the possibility that Gln could be assayed as a therapeutic agent to prevent APAP-induced nephrotoxicity.

Our present results show that Gln pretreatment was able to avoid the renal functional impairment promoted by APAP. Creatinine and urea levels and GFR were preserved with Gln pretreatment. Also, animals pretreated with Gln showed less evidence of histological damage, with less areas of necrosis, no intratubular casts, and preservation of the brush border. Gln treatment produced no changes in normal renal function or histology.

The proximal tubular cells are the main targets of toxic injury to the kidney (Brady et al. 1996). The major function of renal proximal tubular cells is to maintain and regulate the unidirectional transport of ions, water, and organic solutes between the glomerular filtrate and the blood. The polar distribution of $\mathrm{Na}^{+}, \mathrm{K}^{+}$-ATPase to the basolateral membrane is fundamental for adequate $\mathrm{Na}^{+}$reab- sorption (Jørgensen 1986; Molitoris 1992). APAP-treated animals showed an increased abundance of $\mathrm{Na}^{+}, \mathrm{K}^{+}$-ATPase in cortical homogenates. This result has been reported in our previous work (Trumper et al. 2000). In the present work, we also aimed to evaluate the cellular localization of $\mathrm{Na}^{+}, \mathrm{K}^{+}$-ATPase during APAP-induced renal damage. By $\mathrm{Na}^{+}, \mathrm{K}^{+}$-ATPase immunohistochemistry, we observed the basolateral localization of the enzyme in control kidneys. In the APAP-treated kidneys, the signal for $\mathrm{Na}^{+}, \mathrm{K}^{+}$-ATPase was observed in the basolateral and cytoplasmic domains. These findings are in agreement with the loss of cytoskeletal anchorage observed in a previous work (Trumper et al. 2005). The mislocalization of the enzyme, together with the loss of brush border observed in the histological studies, could account for the increased $\mathrm{Na}^{+}$excretion of the APAP-intoxicated animals. The increased delivery of sodium and water to the distal tubules promotes the secretion of potasium in these segments (Giebisch and Wang 2010).

$\mathrm{Na}^{+}, \mathrm{K}^{+}$-ATPase abundance was also increased in the cortical homogenates from rats that received the dual treatment Gln/APAP. Nevertheless, immunohistochemical studies only detected the enzyme in the basolateral domain. The normal polar distribution of $\mathrm{Na}^{+}, \mathrm{K}^{+}$-ATPase and the preserved brush border could account for the normal $\mathrm{Na}^{+}$reabsorption observed in Gln-pretreated rats.

In the kidneys from rats that received the dual treatment Gln/ APAP, some areas of cellular tumefaction were observed. Gln is cotransported into the cells by sodium-dependent mechanisms, which cause the influx of water and cell swelling. Although the mechanism of Gln protection in stress and injury is still unknown, this cell swelling mechanisms were associated with the regulation of gene expression (Schliess et al. 2007).

On the other hand, Gln effectively increased HSP70 abundance in cortical homogenates. As observed in a previous work, APAP induced HSP70 abundance in the cortical tissue (Molinas et al. 2010). The dual treatment Gln/APAP promoted an increase in HSP70 abundance of the same level as that observed in Gln- or APAPtreated animals. HSP70 can exert opposed actions depending on the location of the protein (Rodrigues-Krause et al. 2012). The intracellular localization of HSP70 is required for its function as a molecular chaperone and has a major role in protection against several insults. When cells undergo necrotic death, HSP70 can be released to the extracellular compartment and display a function opposite to its intracellular role (Krause et al. 2015). Further studies to distinguish between the intracellular or extracellular localizarion of HSP70 in our model are needed. Nevertheless, it is remarkable that in spite of the high levels of tissular HSP70 abundance, the appearance of HSP70 was detected only in the urines from APAP-treated animals. As suggested by Mueller et al. (2003), the loss of tubular integrity would be an important factor that results in the appearance of HSP70 in the urine. The loss of tubular cell integrity was also confirmed by the appearance of actin in the urine. Actin was detected only in the urines of APAP-treated animals. The administration of Gln previous to APAP was able to avoid the appearance of both urinary HSP70 and actin. This fact reinforces the observed preservation of renal integrity and function attained with Gln pretreatment. Based on the strong evidence of damage to the tubular cells, it is probably that in kidneys from APAP-intoxicated animals, HSP70 is located extracellularly. In the Gln-pretreated kidneys, where significant less evidence of cellular injury was detected, HSP70 may be localized intracellularly where it plays a role in the maintenance of cellular integrity.

In the present work, we evaluated the inflammatory response to APAP intoxication by measuring MPO activity. APAP-treated animals showed an increased MPO activity in cortical tissue, suggesting that inflammation could play a central role in APAP toxic injury. Gln prevented the increment of MPO induced by APAP. This result could be evidence of the anti-inflammatory effect of Gln. Some authors have shown that Gln attenuation of the inflammatory response and tissue injury is dependent on the expression of HSP70 (Singleton and Wischmeyer 2007). However in our pres- 
ent work, HSP70 was increased at the same levels in the APAP and Gln/APAP groups. On the other hand, Gln is a precursor of glutathione, and glutathione plays an important role in the detoxification of APAP metabolites formed in the liver, but those hepatic glutathione-derived APAP metabolites contribute to the APAPinduced nephrotoxicity (Trumper et al. 1996; Mazer and Perrone 2008). Another precursor of glutathione synthesis as $N$-acetyl cisteine can prevent liver damage but has not shown a beneficial effect on APAP-induced nephrotoxicity (Blakely and McDonald 1995; Mazer and Perrone 2008). The mechanism underlying the protective effects observed for Gln remains to be determined.

In summary, the present study demonstrates the renal protective effects of Gln in APAP-induced nephrotoxicity, supporting the idea that Gln pretreatment could be a therapeutic option to prevent renal functional and structural damage promoted by APAP.

\section{Acknowledgements}

We thank Wiener Laboratories, Rosario, Argentina, for the gift of analytical reagents. This work was supported by SECYT-UNR grant No. 243 to L.T.

\section{References}

Aufricht, C. 2005. Heat-shock protein 70: molecular supertool? Pediatr. Nephrol. 20: 707-713. doi:10.1007/s00467-004-1812-6. PMID:15782306.

Aufricht, C., Lu, E., Thulin, G., Kashgarian, M., Siegel, N.J., and Van Why, S.K. 1998. ATP releases HSP-72 from protein aggregates after renal ischemia. Am. J. Physiol. 274: F268-F274. PMID:9486221.

Bidmon, B., Endemann, M., Müller, T., Arbeiter, K., Herkner, K., and Aufricht, C. 2000. Heat shock protein-70 repairs proximal tubule structure after renal ischemia. Kidney Int. 58: 2400-2407. doi:10.1046/j.1523-1755.2000.00423.x. PMID:11115073.

Blakely, P., and McDonald, B.R. 1995. Acute renal failure due to acetaminophen ingestion: a case report and review of the literature. J. Am. Soc. Nephrol. 6: 48-53. PMID:7579069.

Bonventre, J.V., and Yang, L. 2011. Cellular pathophysiology of ischemic acute kidney injury. J. Clin. Invest. 121: 4210-4221. doi:10.1172/JCI45161. PMID:22045571.

Boyer, T.D., and Rouff, S.L. 1971. Acetaminophen-induced hepatic necrosis and renal failure. JAMA: J. Am. Med. Assoc. 218: 440-441. doi:10.1001/jama.1971. 03190160088021.

Brady, H., Brenner, B., and Lieberthal, W. 1996. Acute renal failure. In The kidney. Edited by B.M. Brenner. Saunders, Philadelphia, Pa. pp. 1200-1252.

Cobden, I., Record, C.O., Ward, M.K., and Kerr, D.N. 1982. Paracetamol-induced acute renal failure in the absence of fulminant liver damage. Br. Med. J. 284: 21-22. doi:10.1136/bmj.284.6308.21.

Coux, G., Trumper, L., and Elías, M.M. 2002. Renal function and cortical $\mathrm{Na}^{+}+\mathrm{K}^{+}-$ ATPase activity, abundance and distribution after ischaemia-reperfusion in rats. Biochim. Biophys. Acta, Mol. Basis Dis. 1586: 71-80. doi:10.1016/S09254439(01)00087-4. PMID:11781151.

Cowley, B.D., and Gudapaty, S. 1995. Temporal alterations in regional gene expression after nephrotoxic renal injury. J. Lab. Clin. Med. 125: 187-199. PMID:7531211.

Curi, R., Lagranha, C.J., Doi, S.Q., Sellitti, D.F., Procopio, J., Pithon-Curi, T.C., et al. 2005. Molecular mechanisms of glutamine action. J. Cell. Physiol. 204: 392401. doi:10.1002/jcp.20339. PMID:15795900.

Donati, Y.R., Slosman, D.O., and Polla, B.S. 1990. Oxidative injury and the heat shock response. Biochem. Pharmacol. 40: 2571-2577. doi:10.1016/0006-2952(90) 90573-4. PMID:2175606.

Fuller, T.F., Rose, F., Singleton, K.D., Linde, Y., Hoff, U., Freise, C.E., et al. 2007. Glutamine donor pretreatment in rat kidney transplants with severe preservation reperfusion injury. J. Surg. Res. 140: 77-83. doi:10.1016/j.jss.2006.10. 021. PMID:17292409.

Giebisch, G.H., and Wang, W.H. 2010. Potassium transport - an update. J. Nephrol. 23: S97-S104. PMID:21170894.

Hamiel, C.R., Pinto, S., Hau, A., and Wischmeyer, P.E. 2009. Glutamine enhances heat shock protein 70 expression via increased hexosamine biosynthetic pathway activity. Am. J. Physiol. Cell Physiol. 297: C1509-C1519. doi:10.1152/ ajpcell.00240.2009. PMID:19776393.

Jørgensen, P.L. 1986. Structure, function and regulation of Na,K-ATPase in the kidney. Kidney Int. 29: 10-20. doi:10.1038/ki.1986.3. PMID:2421041.

Komatsuda, A., Wakui, H., Satoh, K., Yasuda, T., Imai, H., Nakamoto, Y., et al. 1993. Altered localization of 73-kilodalton heat-shock protein in rat kidneys with gentamicin-induced acute tubular injury. Lab. Invest. 68: 687-695. PMID:8515655.

Krause, M., Bock, P.M., Takahashi, H.K., Homem, De, Bittencourt, P.I., and Newsholme, P. 2015. The regulatory roles of NADPH oxidase, intra- and extra- cellular HSP70 in pancreatic islet function, dysfunction and diabetes. Clin. Sci. 128: 789-803. doi:10.1042/CS20140695. PMID:25881670.

Kwon, O., Molitoris, B.A., Pescovitz, M., and Kelly, KJ. 2003, Urinary actin, interleukin-6, and interleukin-8 may predict sustained ARF after ischemic injury in renal allografts. Am. J. Kidney Dis. 41: 1074-1087. doi:10.1016/S02726386(03)00206-3. PMID:12722043.

Laemmli, U.K. 1970. Cleavage of structural proteins during the assembly of the head of bacteriophage T4. Nature, 227: 680-685. doi:10.1038/227680a0. PMID: 5432063.

Mazer, M., and Perrone, J. 2008. Acetaminophen-induced nephrotoxicity: pathophysiology, clinical manifestations, and management. J. Med. Toxicol. 4: 2-6. doi:10.1007/BF03160941. PMID:18338302.

Molinas, S.M., Rosso, M., Wayllace, N.Z., Pagotto, M.A., Pisani, G.B., Monasterolo, L.A., and Trumper, L. 2010. Heat shock protein 70 induction and its urinary excretion in a model of acetaminophen nephrotoxicity. Pediatr. Nephrol. 25: 1245-1253. doi:10.1007/s00467-010-1493-2. PMID:20352459.

Molitoris, B.A. 1992. The potential role of ischemia in renal disease progression. Kidney Int. Suppl. 36: S21-S25. PMID:1319522.

Morrison, A.L., Dinges, M., Singleton, K.D., Odoms, K., Wong, H.R., and Wischmeyer, P.E. 2006. Glutamine's protection against cellular injury is dependent on heat shock factor-1. Am. J. Physiol. Cell Physiol. 290: C1625C1632. doi:10.1152/ajpcell.00635.2005. PMID:16436470.

Mour, G., Feinfeld, D.A., Caraccio, T., and McGuigan, M. 2005. Acute renal dysfunction in acetaminophen poisoning. Renal Failure, 27: 381-383. doi:10.1081/ JDI-65428. PMID:16060123.

Mueller, T., Bidmon, B., Pichler, P., Arbeiter, K., Ruffingshofer, D., VanWhy, S.K., and Aufricht, C. 2003. Urinary heat shock protein-72 excretion in clinical and experimental renal ischemia. Pediatr. Nephrol. 18: 97-99. PMID:12579395.

Pompermayer, K., Souza, D.G., Lara, G.G., Silveira, K.D., Cassali, G.D., Andrade, A.A., et al. 2005. The ATP-sensitive potassium channel blocker glibenclamide prevents renal ischemia/reperfusion injury in rats. Kidney Int. 67: 1785-1796. doi:10.1111/j.1523-1755.2005.00276.x. PMID:15840025.

Rodrigues-Krause, J., Krause, M., O’Hagan, C., De Vito, G., Boreham, C., Murphy, C., et al. 2012. Divergence of intracellular and extracellular HSP72 in type 2 diabetes: does fat matter? Cell Stress Chaperones, 17: 293-302. doi:10. 1007/s12192-011-0319-x. PMID:22215518.

Schierwagen, C., Bylund-Fellenius, A.C., and Lundberg, C. 1990. Improved method for quantification of tissue PMN accumulation measured by myeloperoxidase activity. J. Pharmacol. Methods, 23: 179-186. doi:10.1016/01605402(90)90061-O. PMID:2158602.

Schliess, F., Reinehr, R., and Häussinger, D. 2007. Osmosensing and signaling in the regulation of mammalian cell function. FEBS J. 274: 5799-5803. doi:10. 1111/j.1742-4658.2007.06100.x. PMID:17944941.

Schober, A., Müller, E., Thurau, K., and Beck, F.X. 1997. The response of heat shock proteins 25 and 72 to ischaemia in different kidney zones. Pflügers Arch. Eur. J. Physiol. 434: 292-299. doi:10.1007/s004240050399. PMID:9178629.

Sedmak, J.J., and Grossberg, S.E. 1977. A rapid, sensitive, and versatile assay for protein using Coomassie brilliant blue G250. Anal. Biochem. 79: 544-552. doi:10.1016/0003-2697(77)90428-6. PMID:68686.

Singleton, K.D., and Wischmeyer, P.E. 2007. Glutamine's protection against sepsis and lung injury is dependent on heat shock protein 70 expression. Am. J. Physiol. Regul. Integr. Comp. Physiol. 292: R1839-R1845. doi:10.1152/ajpregu. 00755.2006. PMID:17234954

Trumper, L., Girardi, G., and Elías, M.M. 1992. Acetaminophen nephrotoxicity in male Wistar rats. Arch. Toxicol. 66: 107-111. doi:10.1007/BF02342503. PMID: 1605724

Trumper, L., Monasterolo, L.A., and Elías, M.M. 1996. Nephrotoxicity of acetaminophen in male Wistar rats: role of hepatically derived metabolites. J. Pharmacol. Exp. Ther. 279: 548-554. PMID:8930156.

Trumper, L., Coux, G., and Elías, M.M. 2000. Effect of acetaminophen on $\mathrm{Na}^{+}, \mathrm{K}^{+}$ ATPase and alkaline phosphatase on plasma membranes of renal proximal tubules. Toxicol. Appl. Pharmacol. 164: 143-148. doi:10.1006/taap.2000.8889. PMID:10764627.

Trumper, L., Coux, G., Monasterolo, L.A., Molinas, S., García, V.M., and Elías, M.M. 2005. Effect of acetaminophen on the membrane anchoring of $\mathrm{Na}^{+}, \mathrm{K}^{+}$ ATPase of rat renal cortical cells. Biochim. Biophys. Acta Mol. Basis Dis. 1740: 332-339. doi:10.1016/j.bbadis.2004.09.011. PMID:15949700.

Van Why, S.K., Hildebrandt, F., Ardito, T., Mann, A.S., Siegel, N.J., and Kashgarian, M. 1992. Induction and intracellular localization of HSP-72 after renal ischemia. Am. J. Physiol. 263: F769-F775. PMID:1443167.

Wang, Z., Gall, J.M., Bonegio, R.G., Havasi, A., Hunt, C.R., Sherman, M.Y., et al. 2011. Induction of heat shock protein 70 inhibits ischemic renal injury. Kidney Int. 79: 861-870. doi:10.1038/ki.2010.527. PMID:21270764.

Wischmeyer, P.E., Jayakar, D., Williams, U., Singleton, K.D., Riehm, J., Bacha, E.A., et al. 2003. Single dose of glutamine enhances myocardial tissue metabolism, glutathione content, and improves myocardial function after ischemiareperfusion injury. JPEN: J. Parenter. Enteral Nutr. 27: 396-403. doi:10.1177| 0148607103027006396. PMID:14621120.

Ziegler, T.R., Ogden, L.G., Singleton, K.D., Luo, M., Fernandez-Estivariz, C. Griffith, D.P., et al. 2005. Parenteral glutamine increases serum heat shock protein 70 in critically ill patients. Intensive Care Med. 31: 1079-1086. doi:10. 1007/s00134-005-2690-5. PMID:15973519. 